\title{
Comunicação
}

\section{Produção vegetal e de óleo essencial de boldo pequeno em função de fontes de adubos orgânicos ${ }^{1}$}

\author{
Louise Ferreira Rosal², José Eduardo Brasil Pereira Pinto*3, Suzan Kelly Vilela Bertoluccit, \\ Renata da Silva Brant ${ }^{5}$, Edenilson dos Santos Niculau ${ }^{6}$, Péricles Barreto Alves ${ }^{7}$
}

\section{RESUMO}

A aplicação de fertilizantes orgânicos, em plantas medicinais e aromáticas, normalmente modifica positivamente a produção vegetal e de óleo essencial. Neste contexto, tendo por fim avaliar a resposta de plantas de Plectranthus neochilus Schltr., cultivadas com diferentes fontes de adubos orgânicos, o presente trabalho estudou a produção de biomassa, teor, rendimento e composição química do óleo essencial. As mudas, após a aclimatização, foram transplantadas para vasos de dez litros, acondicionados em casa de vegetação. O experimento foi constituído por quatro tratamentos e quatro repetições (16 parcelas), sendo cada parcela composta por cinco vasos. Os tratamentos foram: ausência de adubo orgânico (testemunha); aplicação de $60 \mathrm{t} \mathrm{ha}^{-1}$ de esterco bovino; $30 \mathrm{t} \mathrm{ha}^{-1}$ de esterco avícola; $60 \mathrm{t} \mathrm{ha}^{-1}$ de composto orgânico. Aos 120 dias de cultivo, as plantas foram colhidas e uma parte das folhas frescas foi destinada à extração do óleo essencial. O restante do material vegetal foi seco em estufa, até atingir peso constante, para a determinação da biomassa seca. As análises químicas do óleo foram realizadas por cromatografia gasosa (CG-DIC e CG-EM). As fontes de adubo orgânico testadas promoveram diferenças entre os tratamentos em relação à produção de biomassa, rendimento e composição do óleo essencial de P. neochilus. A utilização de diferentes fertilizantes orgânicos não modificou o teor de óleo volátil.

Palavras-chave: Plectranthus neochilus Schltr., fertilizante orgânico, produção de biomassa, óleo volátil.

\section{ABSTRACT}

\section{Effect of organic fertilizer sources on biomass and essential oil production of Plectranthus neochilus Schlechter}

Application of organic fertilizers to medicinal aromatic plants usually has a positive effect on biomass and essential oil production. Plectranthus neochilus Schlechter was cultivated with three organic fertilizer sources. This study evaluated the biomass production and content, yield and chemical composition of the essential oil. The seedlings, after acclimatization, were transplanted to $10 \mathrm{~L}$ pots and placed under a protected environment. The experiment consisted of four treatments and four replications, with five pots per plot. The treatments included: without organic fertilizer (control); cattle manure $60 \mathrm{t} \mathrm{ha}^{-1}$; chicken manure $30 \mathrm{t} \mathrm{ha}^{-1}$; and organic compost $60 \mathrm{t} \mathrm{ha}^{-1}$. Plants were harvested at 120 days after planting. Part of the fresh leaves was used for the essential oil extraction and the remaining material was

\footnotetext{
Recebido para publicação em 29/07/2009 e aprovado em 21/06/2011

Trabalho extraído da tese de doutorado apresentada ao programa de pós-graduação em Fitotecnia pela Universidade Federal de Lavras.

2Engenheira-Agrônoma,Doutora. Instituto Federal de Educação, Ciência e Tecnologia do Pará (IFPA), Campus Castanhal, Bairro Saudade, Rod. BR316, Km 62, Castanhal, Pará. louise_rosal@yahoo.com.br

${ }^{3}$ Engenheiro-Agrônomo, Ph.D. Departamento de Agricultura, Laboratório de Cultura de Tecidos e Plantas Medicinais, Caixa Postal 3037, 37.200-000, Lavras, Minas Gerais, Brasil. jeduardo@dag.ufla.br. "Autor para correspondência

${ }^{4}$ Farmacêutica, Doutora. Departamento de Agricultura, Laboratório de Cultura de Tecidos e Plantas Medicinais, CP 3037, 37.200-000, Lavras, Minas Gerais, Brasil. suzan @ dag.ufla.br ${ }_{5}^{5}$ Engenheira-Agrônoma, Doutora. Sistemas Sustentáveis de Produção Vegetal, EMBRAPA Cocais, Edifício INCRA, Av. Santos Dumont, 18, Bloco 3, Anil, 65046-660, São Luis, Maranhão, Brasil. renata.brant@embrapabr

${ }^{6}$ Quimico, Mestre. Universidade Federal de Sergipe, Av. Marechal Rondon, s/n, 49.100-000, São Cristovão, Sergipe, Brasil. edenilsonnicolau@hotmail.com

Quimico, Doutor. Departamento de Química, Universidade Federal de Sergipe, Av. Marechal Rondon, s/n, 49.100-000, São Cristovão, Sergipe, Brasil. pericles@ufs.br
} 
oven-dried for dry mass determination. The oil composition was determined by gas chromatography-mass spectrometry (CG-MS). The organic fertilizer sources showed differences between treatments related to biomass production, biomass distribution, essential oil yield and chemical composition in Plectranthus neochilus. The use of different organic ferilizers did not change the content of volatile oil.

Key words: Biomass, Plectranthus neochilus Schlechter, organic fertilizers.

\section{INTRODUÇÃO}

Plectranthus neochilus (Lamiaceae) é uma planta herbácea, conhecida, vulgarmente, como boldo pequeno, boldo rasteiro ou boldo gambá. Possui folhas pequenas, quase triangulares, dispostas compactamente, levemente amargas e de odor forte, principalmente quando está florida (Lorenzi \& Matos, 2002). É usada popularmente para o tratamento de insuficiência hepática e dispepsia (Duarte $\&$ Lopes, 2007). Informações sobre produtividade vegetal, teor, rendimento e composição química do óleo essencial dessa espécie são incipientes na literatura.

A produção de biomassa e síntese de princípios ativos nas plantas medicinais, aromáticas e condimentares depende de vários fatores, dentre eles o fator genético, clima, condições edáficas e manejos culturais. Entre os fatores que interferem na composição química da planta, a nutrição merece destaque, pois a deficiência ou o excesso de nutrientes pode interferir na produção de biomassa e na quantidade de princípio ativo (Mapell et al., 2005). A adubação orgânica das plantas medicinais, além de ser parte essencial nos sistemas de cultivo orgânico, fornece nutrientes para as plantas e proporciona benefícios na estrutura física, química e biológica do solo.

Pesquisas fitoquímicas têm sido o foco de diversos estudos na área de plantas medicinais e aromáticas (Javidnia et al., 2007; Tajbakhsh et al., 2007; Habibi et al., 2008). Frequentemente, encontram-se na literatura descrições da composição química dessas espécies. No entanto, faz-se necessário, paralelamente a esses estudos, considerar as possíveis variações quantitativas e qualitativas que podem ocorrer na biossíntese dos metabólitos secundários, em resposta à aplicação de técnicas agronômicas. Portanto, estudos que envolvem adubação, em espécies produtoras de óleos essenciais, não objetivam apenas a produção de biomassa, mas, conjuntamente, busca-se esclarecer as alterações que esses insumos podem ocasionar ao teor, ao rendimento e à composição química do óleo.

Nesse sentido, estudos sobre o rendimento de biomassa e óleo essencial, em respostas à adubação orgânica, mineral e mista, vêm sendo desenvolvidos com espécies medicinais, aromáticas e condimentares, tais como: Origanum vulgare L. (Corrêa et al., 2010), Plectranthus neochilus (Rosal et al., 2009), Ocimum selloi Benth. (Costa et al. 2008a), Hyptis suaveolens (L.) Poit. (Maia et al., 2008) e Ocimum basilicum L. (Blank et al., 2005).

Portanto, objetivou-se, neste trabalho, verificar o efeito de diferentes fontes de adubos orgânicos no crescimento vegetativo, no teor, no rendimento e na composição química do óleo essencial de boldo pequeno.

\section{MATERIAL E MÉTODOS}

\section{Instalação do experimento}

O experimento foi instalado em estufa plástica de 18,5 x 13 m, posição norte-sul, do Laboratório de Cultura de Tecidos Vegetais e Plantas Medicinais do Departamento de Agricultura, da Universidade Federal de Lavras (DAG/ UFLA), situada na região sul de Minas Gerais, a 918 m de altitude, latitude $21^{\circ} 14^{\prime} \mathrm{S}$ e longitude $45^{\circ} 00^{\prime} \mathrm{W}$ GRW.

As mudas do material vegetal originaram-se de plantas matrizes de P. neochilus, pertencentes ao Horto Medicinal do DAG/UFLA. A planta matriz foi herborizada e incorporada, sob o número 22858, ao Herbário ESAL, do Departamento de Biologia da UFLA.

As mudas de boldo foram produzidas a partir de estacas apicais, com aproximadamente $5 \mathrm{~cm}$ de comprimento, e postas para enraizar em bandejas de poliestireno de 72 células, contendo o substrato comercial Plantmax ${ }^{\circledR}$. As mudas foram cultivadas em ambiente protegido, com $60 \%$ de sombreamento, durante 30 dias, período suficiente para que todas estivessem bem estabelecidas e enraizadas. As mudas foram transplantadas para vasos de dez litros, com solo misturado com os adubos orgânicos.

O delineamento experimental adotado foi inteiramente casualizado, com quatro tratamentos, constituídos de quatro repetições e cinco plantas por parcela (uma planta/vaso). Os tratamentos foram: ausência de adubo orgânico (testemunha); aplicação de $60 \mathrm{t} \mathrm{ha}^{-1}$ de esterco bovino; $30 \mathrm{t} \mathrm{ha}^{-1}$ de esterco avícola; $60 \mathrm{t} \mathrm{ha}^{-1}$ de composto orgânico. As doses utilizadas neste ensaio foram baseadas nas recomendações normalmente utilizadas para o cultivo de plantas medicinais (Lameira \& Pinto, 2008) e projetadas para $\mathrm{t} / \mathrm{h}$. A compostagem foi feita, utilizando-se, como matéria prima, capim e outros restos vege- 
tais de plantas (Carvalho, 2007). A irrigação foi realizada até o solo atingir a capacidade de campo, três vezes por semana.

O solo utilizado como substrato foi coletado da camada de 0-20 cm de profundidade, de um Latossolo Vermelho-Amarelo distrófico (LVAd) (EMBRAPA, 2006), do município de Lavras. Realizaram-se as análises do solo e dos substratos no Laboratório de Análises Química e Física do Solo, do Departamento de Ciência do Solo, da UFLA. A caracterização química e física das amostras de solo foi realizada conforme EMBRAPA (1997) e a caracterização química dos substratos utilizados como adubos foram realizadas, segundo metodologia de Silva (1999). As características químicas do solo e dos adubos orgânicos foram determinadas e obtiveram-se os seguintes resultados para o solo: $\mathrm{pH}$ em água $=6,1 ; \mathrm{P}$ e K $\left(\mathrm{mg} \mathrm{dm}^{-3}\right)=4,9$ e 7,6; $\mathrm{Ca}^{2+}, \mathrm{Mg}^{2+}$, $\mathrm{Al}^{3+}, \mathrm{H}+\mathrm{Al}\left(\mathrm{cmol}_{\mathrm{c}} \mathrm{dm}^{-3}\right)=3,1 ; 0,9 ; 0,0 ; 1,5 ;$ índice de saturação de bases $(\%)=73,6$; matéria orgânica 1,6 (dag $\left.\mathrm{kg}^{-1}\right) ; \mathrm{Zn}, \mathrm{Fe}, \mathrm{Mn}, \mathrm{Cu}, \mathrm{B}$ e S $\left(\mathrm{mg} \mathrm{dm}^{-3}\right)=7,7 ; 44,4 ; 37,8$; 4,$5 ; 0,3 ; 40,3$, respectivamente. Os adubos orgânicos, por sua vez, também foram analisados, gerando os seguintes valores para a compostagem: $\mathrm{N}, \mathrm{P}, \mathrm{K}, \mathrm{Ca}$ e $\mathrm{Mg}$ $\left(\right.$ g. $\left.\mathrm{kg}^{-1}\right)=5,0 ; 0,6 ; 23,8 ; 5,1$ e 3,6; S, B, Ca, Fe, Mn e Zn $\left(\mathrm{mg} \mathrm{kg}^{-1}\right)=0,5 ; 19,0 ; 60,0 ; 79.169 ; 398 ; 217$, respectivamente. Para esterco bovino: $\mathrm{N}, \mathrm{P}, \mathrm{K}, \mathrm{Ca}$ e $\mathrm{Mg}\left(\mathrm{g} . \mathrm{kg}^{-1}\right)=$ $14 ; 3,2 ; 19,2 ; 11,5$ e $3 ; \mathrm{S}, \mathrm{B}, \mathrm{Ca}, \mathrm{Fe}, \mathrm{Mn}$ e Zn $\left(\mathrm{mg} \mathrm{kg}^{-1}\right)=$ 2,$2 ; 22,4 ; 23,6 ; 16.854 ; 273 ; 90,5$, respectivamente. Para esterco avícola: $\mathrm{N}, \mathrm{P}, \mathrm{K}, \mathrm{Ca}$ e $\mathrm{Mg}\left(\mathrm{g} . \mathrm{kg}^{-1}\right)=25,8 ; 25,7$; 22,$2 ; 102,5 ; 6,1 ; \mathrm{S}, \mathrm{B}, \mathrm{Ca}, \mathrm{Fe}, \mathrm{Mn}$ e Zn $\left(\mathrm{mg} \mathrm{kg}^{-1}\right)=5,2 ; 35$; 68; 2.186; 552 e 503, respectivamente.

Após 120 dias de cultivo, as plantas foram colhidas e uma parte das folhas frescas coletadas, aleatoriamente, foi destinada à extração do óleo essencial. O horário de colheita do material destinado à obtenção do óleo foi, rigorosamente, o mesmo durante os dias da colheita do experimento, às oito horas da manhã. As plantas colhidas foram separadas em raiz, caule e folha, para secagem até peso constante, para obtenção da biomassa seca.

\section{Extração do óleo essencial}

O óleo essencial das folhas frescas foi extraído pelo processo de hidrodestilação, em aparelho de Clevenger, sendo utilizados $200 \mathrm{~g}$ por repetição, em $700 \mathrm{~mL}$ de água destilada, por 120 minutos.

O hidrolato obtido de cada hidrodestilação foi submetido à partição líquido-líquido, em funil de separação, com três porções de $15 \mathrm{~mL}$ de diclorometano. As frações orgânicas de cada repetição foram reunidas e secas com sulfato de magnésio anidro em excesso. $\mathrm{O}$ sal foi removido por filtração simples e o solvente evaporado, à temperatura ambiente, em capela de exaustão de gases, até peso constante.
Diante da massa obtida, determinaram-se o teor do óleo essencial de $P$. neochilus, na base úmida das folhas [T\% = massa do óleo $(\mathrm{g}) / 200 \mathrm{~g}$ x 100], e o rendimento de óleo por planta $\left[\mathrm{R}\left(\mathrm{g} \cdot\right.\right.$ planta $\left.^{-1}\right)=$ massa do óleo $(\mathrm{g}) \mathrm{x}$ massa das folhas $(\mathrm{g}) / 200 \mathrm{~g}]$.

\section{Identificação da composição química dos óleos essenciais}

As amostras de óleo essencial foram analisadas por cromatografia gasosa (CG), utilizando-se aparelho Shimadzu 17A, equipado com detector de ionização de chama (DIC) e, também, por cromatografia gasosa acoplada à espectrometria de massa (CG-EM), usando-se aparelho Shimadzu QP5050A. As condições cromatográficas foram coluna capilar de sílica fundida, com fase estacionária DB-5MS (30 m x 0,2 mm x 0,25 $\mu \mathrm{m}$ de espessura do filme); He nas análises por CG-EM como gás de arraste com fluxo de 1,0 $\mathrm{mL} \mathrm{min}^{-1}$, a temperatura foi programada mantendo-se $60^{\circ} \mathrm{C}$ por $1,5 \mathrm{~min}$, aumentando-se para 246 ${ }^{\circ} \mathrm{C}$ a $3{ }^{\circ} \mathrm{C} \mathrm{min}$ min $^{-1}$, então aquecendo-se para $270{ }^{\circ} \mathrm{C}$ a $10{ }^{\circ} \mathrm{C}$ $\min ^{-1}$ e mantendo-se esta temperatura constante por $5 \mathrm{~min}$.; as temperaturas do injetor e do detector foram $220{ }^{\circ} \mathrm{C}$ e $240{ }^{\circ} \mathrm{C}$, respectivamente; o volume de injeção foi $0,2 \mu \mathrm{L}$ ( $20 \%$ de solução de $\mathrm{CH}_{2} \mathrm{Cl}_{2}$ ), com velocidade de arraste de 1,5 $\mathrm{mL} \mathrm{min}^{-1}$. As condições do EM foram detector de captura iônica, operando por impacto eletrônico, e energia de impacto de $70 \mathrm{e}-\mathrm{V}$. A velocidade de varredura foi de 0,5 scan $\operatorname{seg}^{-1}$ de 40 a $550 m z^{-1}$. Cada componente foi identificado pela comparação dos espectros de massas obtidos com os dados de espectroteca on-line NIST 69 e dados da literatura (Adams, 2007). Os índices de retenção de Kovats (IK) foram determinados, utilizando-se uma curva de calibração de uma série de $n$-alcanos $\left(\mathrm{C}_{8}-\mathrm{C}_{32}\right)$, injetados nas mesmas condições cromatográficas das amostras, com aplicação da equação de Dool \& Kratz (1963). Os valores de retenção obtidos foram confrontados com dados da literatura (Adams, 2007). A concentração dos constituintes foi calculada por meio da área integral de seus respectivos picos, relacionada com a área total de todos os constituintes da amostra, obtida pela análise cromatográfica a gás (CG) com detector de ionização de chamas (DIC).

\section{Análise estatística}

Os dados obtidos foram submetidos à análise de variância, pelo teste de F, e a comparação de médias feita pelo teste de Scott-Knott $(\mathrm{p}<0,05)$.

\section{RESULTADOS E DISCUSSÃO}

\section{Análise de crescimento}

Estudos realizados por nossa equipe com P. neochilus, cultivados em campo, com aumento dos níveis de esterco 
bovino testados, promoveram aumento linear na produção de biomassa e no rendimento do óleo essencial (Rosal et al., 2009). Com base nesses resultados, avaliaram-se, no presente trabalho, diferentes fontes de adubos orgânicos.

As plantas foram colhidas aos 120 dias, o período de condução do experimento baseou-se no fato de que plantas cultivadas em vaso podem ter seu crescimento limitado pelo menor volume disponível para expansão do sistema radicular, reduzindo-se assim o tempo de permanência nessas condições.

As plantas de $P$. neochilus responderam positivamente ao crescimento e ao desenvolvimento vegetativo, em relação às diferentes fontes de adubação orgânica. A maior produção de ramos foi observada nas plantas cultivadas com adubo avícola (Figura 1). As fontes de adubo orgânico utilizadas promoveram diferenças significativas na produção de biomassa entre os tratamentos (Figura 2). As plantas cultivadas com esterco avícola apresentaram expressivo acúmulo de biomassa seca em relação às demais.

A produção de biomassa seca total nas plantas adubadas com esterco avícola foi 12,43 vezes maior que a do tratamento utilizado como controle (ausência de adubo) e, em relação ao esterco bovino e ao composto foi 8,33 e 3,31 vezes superior, respectivamente. A eficiência nutricional depende de vários fatores, tais como os climáticos, os edáficos, aqueles intrínsecos às espécies e suas interações com o meio ambiente, aqueles relacionados com a matéria orgânica do solo e, ou, com a composição química do adubo utilizado, dentre outros que afetam a absorção e a utilização de nutrientes pelas plantas (Fageria, 1998). O esterco proveniente da avicultura de criações intensivas, nas quais os animais são alimentados com ração, é rico em nutrientes, especialmente nitrogênio e fósforo, mas pobre em celulose e em lignina. Por isso, sua decomposição é rápida, liberando em poucos dias a maior parte dos nutrientes (Souza \& Rezende, 2006).

Evidencia-se, portanto, que a obtenção do composto orgânico de interesse está relacionada com a espécie vegetal, adubação (tipo de adubo e níveis), além de outras variáveis ambientais que não foram estudadas neste trabalho como luz, temperatura, fotoperíodo e manejo fitotécnico.

Costa et al. (2008b) avaliaram os efeitos do adubo químico, do composto orgânico, do esterco bovino e do esterco avícola na produção de biomassa de capim-limão (Cymbopogon citratus (DC.) Stapf), demonstrando que, nas condições estudadas, o esterco de aves resultou em maior acúmulo de biomassa seca total. Também com a finalidade de determinar a influência de esterco bovino e de aves no desenvolvimento de Hyptis suaveolens, Maia et al. (2008) concluíram que a produti- vidade foi superior quando as plantas foram fertilizadas com esterco avícola.

Em contrapartida, Palácio et al. (2007) investigaram a influência da ausência e da utilização de fontes de nitrogênio (ureia e esterco ovino), na produção de biomassa, em Baccharis trimera (Less.) DC., e observaram que não houve diferenças significativas para o rendimento da matéria seca. Já para o manjericão (Ocimum basilicum cv. Genovese), fertilizado com adubo mineral, duas fontes de adubos orgânicos (esterco bovino e avícola), aplicados separadamente ou misturados, a melhor resposta para a produção de matéria seca foi alcançada com a mistura do fertilizante químico com o esterco de aves (Blank et al., 2005).

Fazendo-se uma comparação entre os adubos orgânicos utilizados no presente estudo, observou-se que o desenvolvimento das plantas fertilizadas com composto orgânico foi inferior em relação ao das cultivadas com estercos avícola e bovino (Figura 1). Análise química dos adubos evidenciou grande diferença no teor de nutrientes dessas fontes de adubação. Analisando-se o teor de nitrogênio e fósforo, observou-se que o esterco avícola apresentou os maiores valores e o teor de potássio foi similar nos três adubos. O esterco avícola apresentou um conteúdo de $\mathrm{N}$ de 5,2 e 1,8 vezes maior em relação ao composto orgânico e ao esterco bovino, respectivamente. Para o P, esse teor foi de 42,8 e 8,0 vezes em relação ao composto orgânico e ao esterco bovino, respectivamente.

Pesquisas que relacionem o tipo e a quantidade de adubo suficiente para garantir produções elevadas e de qualidade, aliadas à viabilidade econômica, ainda necessitam de maiores refinamentos. As espécies medicinais e aromáticas normalmente apresentam uma correlação positiva entre aumento dos níveis de insumos aplicados e produção de biomassa (Costa et al., 2008a; b; Maia et al., 2008; Corrêa et al., 2010). No entanto, devem-se conside-

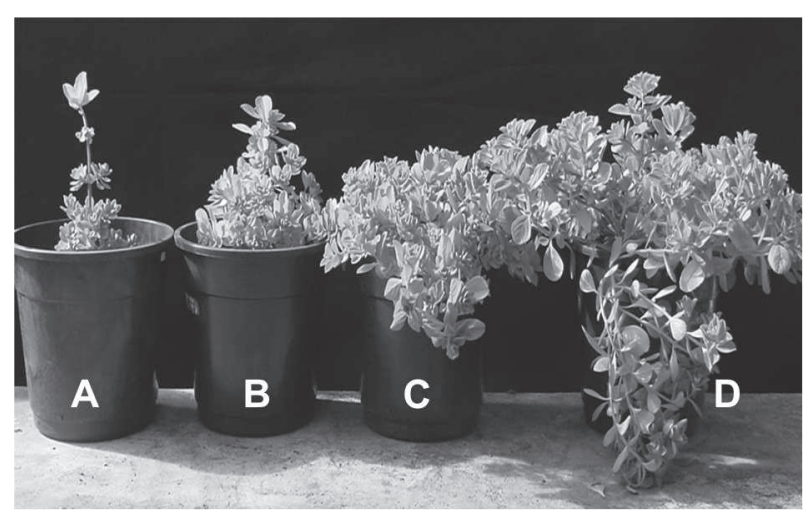

Figura 1. Plantas de Plectranthus neochilus cultivadas em casa de vegetação sob os seguintes tratamentos: A) ausência de fertilizante; B) 60 t ha-1 de composto orgânico; C) $60 \mathrm{t} \mathrm{ha}^{-1} \mathrm{de}$ esterco bovino; D) $30 \mathrm{t} \mathrm{ha}^{-1}$ de esterco avícola. 
rar a fonte e a dose que acarretarão maior retorno para o produtor.

Quanto à relação R:PA, nas diferentes fontes de adubo orgânico, os maiores valores foram obtidos no tratamento sem adubação, verificando-se diminuição da relação R:PA com o uso de compostagem, esterco bovino e esterco avícola, respectivamente (Figura 2). Este resultado indica que a fonte de adubo orgânico com mais nutrientes direciona a distribuição de biomassa para a parte aérea da planta. Pode-se afirmar que o cultivo de boldo pequeno, nas diferentes condições de cultura, provocou mudança na relação parte aérea e raiz. $\mathrm{O}$ aporte de maior teor de nutrientes, proporcionado pela adubação com esterco avícola, gerou um crescimento na parte aérea das plantas que se destacou da biomassa seca da raiz.

Um perfil para os valores de biomassa seca total foi construído, apresentando diferenças entre os tratamentos quanto ao desenvolvimento dos caules e raízes, não diferindo entre si. As folhas concentraram mais de $47 \%$ da matéria seca total (Figura 3). A relação fonte-dreno foi observada quando se utilizaram diferentes fontes de adubos orgânicos. A percentagem de biomassa seca na folha não diferiu entre os tratamentos (Figura 3). Entretanto, nos caules, houve maior percentagem de biomassa seca em plantas fertilizadas com esterco avícola. Os resultados evidenciaram um forte dreno da parte aérea para a raiz, à medida que o adubo apresentou menor teor de nutrientes. Tal fato pode estar relacionado com um mecanismo de sobrevivência, desenvolvido pelas plantas, com maior investimento no sistema radicular, tendo em vista a maior exploração do solo, em vista dos baixos níveis de nutrientes no ambiente de cultivo. Ao comparar a biomassa seca da parte aérea entre os tratamentos, observou-se que os maiores acúmulos ocorreram nas plantas adubadas com

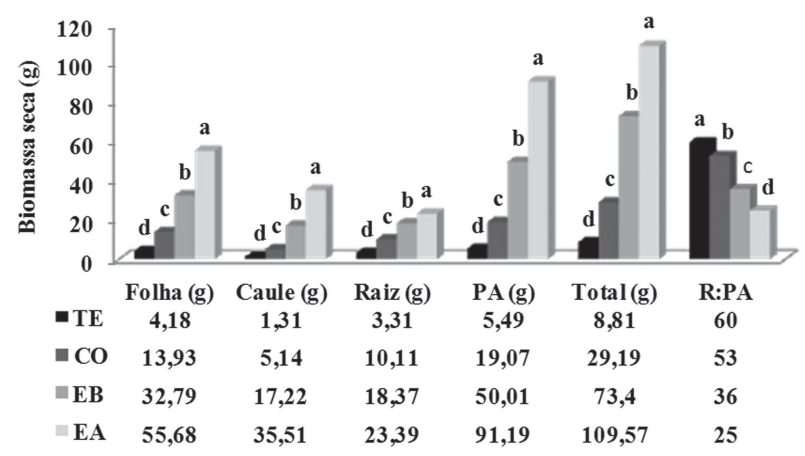

Figura 2. Biomassa seca das folhas, caules, raízes, parte aérea (PA) e total (gramas) de plantas de Plectranthus neochilus cultivadas em vasos, em casa de vegetação, sob os seguintes tratamentos: ausência de fertilizante - testemunha (TE); $60 \mathrm{t} \mathrm{ha}^{-1}$ de composto orgânico (CO); 60 t ha $^{-1}$ de esterco bovino (EB); 30 t ha $^{-1}$ de esterco avícola (EA). Médias seguidas pela mesma letra não diferem entre si pelo teste de Scott-Knott ( $\mathrm{p}<0,05)$.

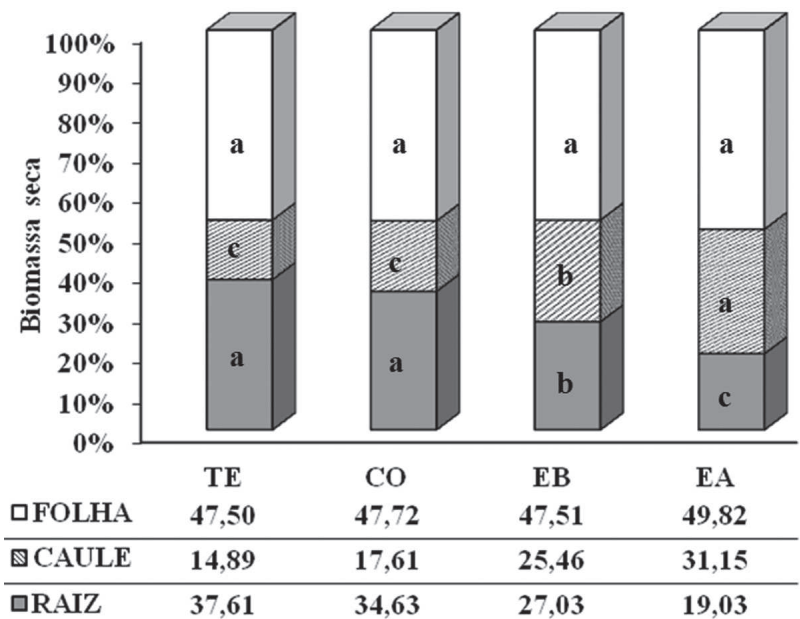

Figura 3. Percentagem de biomassa seca de folhas, caule e raiz de plantas de Plectranthus neochilus cultivadas em vasos, em casa de vegetação, sob os seguintes tratamentos: ausência de fertilizante - testemunha (TE); 60 t ha $^{-1}$ de composto orgânico (CO); 60 t ha${ }^{1}$ de esterco bovino (EB); 30 tha ${ }^{-1}$ de esterco avícola (EA). Médias seguidas pela mesma letra na horizontal não diferem entre si pelo teste de Scott-Knott $(\mathrm{p}<0,05)$.

esterco de boi $(70,97 \%)$ e avícola $(80,97 \%)$, em detrimento da testemunha $(62,39 \%)$ e do composto orgânico $(65,33 \%)$ (Figura 3). À medida que a fonte de esterco apresentava maior teor de nutrientes, a relação fonte-dreno foi observada em direção ao acúmulo de matéria seca na parte aérea. No entanto, quando o teor de nutriente foi reduzido no esterco, a relação fonte-dreno favoreceu o acúmulo de biomassa da raiz.

Respostas similares foram verificadas em estudos com Hyptis suaveolens, que indicaram diferenças para a distribuição da biomassa seca entre folhas, caules e raízes de plantas adubadas com duas fontes de adubos orgânicos: estercos bovino e avícola, com acúmulo de fotoassimilados ocorrendo, preferecialmente, na parte aérea (Maia et al., 2008). O melhor desenvolvimento das plantas adubadas com esterco de aves também foi observado por Costa et al. (2008a), Maia et al. (2008) e Corrêa et al. (2010).

\section{Teor, rendimento e identificação da composição química dos óleos essenciais}

A hidrodestilação das folhas frescas de $P$. neochilus proporcionou um óleo essencial de cor amarelada, com um forte odor característico da planta, mas com um baixo teor, variando de 0,007 a 0,01\%, provavelmente em função da alta umidade presente nas folhas (cerca de 94\%). Em relação ao teor de óleo essencial de $P$. neochilus, não foram verificadas diferenças entre os tratamentos (Figura 4). Estes resultados concordam com os obtidos por Carvalho et al. (2005) e Palácio et al. (2007). No entanto, Silva et al. (2007), ao avaliar o efeito da ausência de adubação, da aplicação de esterco bovino e de adubo químico sobre a percentagem de óleo essencial de Baccharis trimera, 
verificaram que, quando não se utilizou nenhuma adubação, houve tendência de aumento no teor de óleo. Estudo realizado com orégano (Origanum vulgare) indicou maior teor de óleo essencial com maiores doses de adubo orgânico (Corrêa et al., 2010).

O rendimento de óleo essencial extraído das folhas frescas de $P$. neochilus aumentou com a utilização de diferentes fontes de adubos orgânicos, por causa de sua relação direta com a produção de biomassa vegetal (Figura 4). O rendimento de óleo apresentou uma correlação positiva com a produção de biomassa das folhas, visto que os teores de óleo não apresentaram diferenças significativas. Essa relação foi citada por Sales et al. (2009) e Corrêa et al. (2010), os quais apontaram que o rendimento de óleo essencial em Hyptis marrubioides Epling e Origanum vulgare, respectivamente, foi aumentado quando se obtiveram maiores produções de biomassa nas plantas cultivadas.

Nas plantas de boldo pequeno, a quantidade de óleo por planta, nos tratamentos fertilizados com esterco avícola foi, em média, 11,36 vezes maior em relação ao das plantas que não foram adubadas. Entre as fontes de adubo, o esterco avícola foi 1,76 e 4,59 vezes maiores que o esterco bovino e o composto orgânico, respectivamente.

Não há na literatura um consenso em relação à resposta do rendimento de óleo essencial frente ao uso de diferentes tipos de adubos e, muito menos, de doses. Isso pode estar relacionado com o fato de as plantas medicinais compreenderem um amplo e diversificado grupo de espécies, com grande variabilidade quanto à produção de metabólitos secundários, cuja biossíntese varia em função de fatores extrínsecos e intrínsecos à espécie. As possibilidades de resultados contraditórios são expressivas.

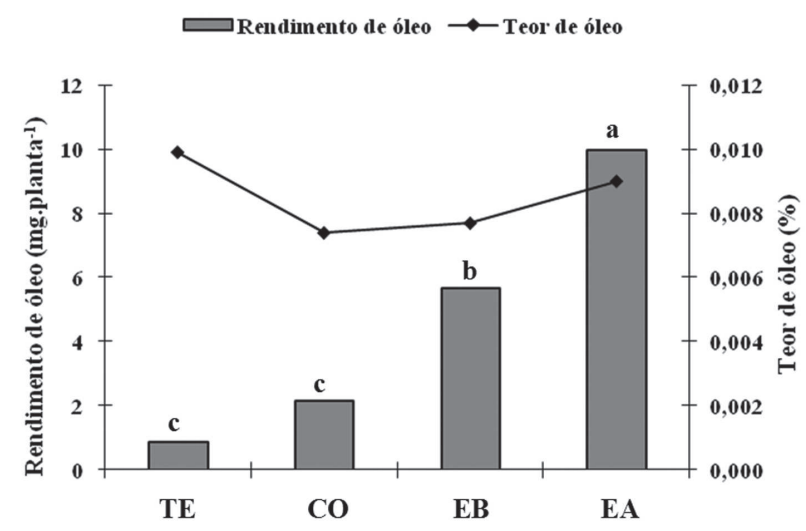

Figura 4. Rendimento (mg.planta ${ }^{-1}$ ) e teor (\%) de óleo essencial de plantas de Plectranthus neochilus cultivadas em vasos, em casa de vegetação, sob os seguintes tratamentos: ausência de fertilizante - testemunha (TE); $60 \mathrm{t} \mathrm{ha}^{-1}$ de composto orgânico (CO); 60 t ha $^{-1}$ de esterco bovino (EB); 30 tha $^{-1}$ de esterco avícola (EA). Barras com a mesma letra não diferem entre si pelo teste de Scott-Knott $(\mathrm{p}<0,05)$.
A análise química do óleo essencial de $P$. neochilus resultou numa significativa diversidade de constituintes. Pela análise dos perfis cromatográficos, observaram-se 39, 17 e 26 picos, nos ensaios sem adubação, com adubação bovina e avícola, respectivamente, dos quais identificados 31,15 e 21 constituintes químicos (Tabela 1). Como já demonstrado anteriormente, no tratamento sem adubação, o desenvolvimento da parte aérea foi bem inferior ao dos demais (Figura 1). Pode-se inferir que as plantas submetidas a um estresse nutricional, por não terem sido adubadas com a quantidade suficiente para promover o seu crescimento e desenvolvimento, sintetizaram mais compostos para sua defesa ou sobrevivência. Infelizmente, não foi possível obter análise do óleo essencial da folha proveniente da adubação com o composto orgânico, pela pequena quantidade obtida.

Simões \& Spitzer (2007) citaram que os compostos terpênicos mais frequentes nos óleos essenciais são os monoterpenos (cerca de 90\%) e os sesquiterpenos. Todavia, no óleo essencial de $P$. neochilus foram preponderantes os sesquiterpenos, variando entre 88,91 e $93,56 \%$ e, os monoterpenos, apenas de 1,88 a 2,76\%.

Podem-se destacar sete constituintes majoritários, totalizando $62,99 \%$ da área relativa dos picos no tratamento controle: $\beta$-cariofileno $(15,06 \%)$, germacreno-D $(9,44 \%), \delta$-cadineno $(7,38 \%)$, E-nerolidol $(5,71 \%)$, óxido de cariofileno $(9,83 \%)$, cubenol $(7,43 \%)$ e $\alpha$-cadinol $(8,14 \%)$. No tratamento com adubação bovina, foram quatro constituintes majoritários, totalizando $73,33 \%$, sendo: óxido de cariofileno (33,53\%), 1-epi-cubenol $(5,74 \%)$, cubenol $(13,67 \%)$ e $\alpha$-cadinol (20,39\%). Já no tratamento com adubação avícola, foram três constituintes que mais destacaram, sendo eles o óxido de cariofileno (43,70\%), o cubenol $(8,62 \%)$ e o $\alpha$-cadinol $(11,93 \%)$, totalizando $64,25 \%$ (Tabela 1).

Outros trabalhos corroboram os resultados encontrados com boldo pequeno. Trabalhos com orégano (Corrêa et al., 2010) e elixir paregórico (Costa et al., 2008a), com adubação orgânica, com estercos bovino e avícola, evidenciaram alterações no número e na percentagem relativa dos constituintes químicos, corroborando Simões \& Spitzer (2007), quanto a que tipo de cultivo influencia na composição química dos óleos essenciais.

Os compostos majoritários encontrados no óleo essencial de $P$. neochilus têm várias propriedades farmacológicas (antimicrobiana, larvicidas, entre outras). Em estudos com Cordia verbenacea DC., o cariofileno mostrou atividade anti-inflamatória em ensaios farmacológicos em ratos (Fernandes et al., 2007). Outros estudos mostraram atividades inibitória da colite ulcerativa e da irritação da mucosa gástrica, por meio da administração oral de cariofileno, em ratos com colite ulcerativa e mucosa gástrica irritada induzida (Cho et al., 2007). 
Outro componente encontrado em grande quantidade, principalmente com adubação orgânica $(33,53$ e $43,70 \%$ ), foi o óxido de cariofileno. Este constituinte sesquiterpênico apresentou atividade antifúngica, em modelo experimental in vitro, contra três espécies de Trichophyton, causador de infecções micóticas nos pés (Yang et al., 1999). O óxido de cariofileno, o qual é encontrado em muitos óleos essenciais de plantas, foi aprovado pelo FDA como conservante de alimentos, drogas e cosméticos (FDA, 1973).

$\mathrm{O} \alpha$-cadinol do óleo essencial de P. neochilous variou de 8,14 a $20,39 \%$. E este bioativo tem demonstrado ter uma atividade antifúngica efetiva. Chang et al. (2003) observaram uma atividade inibitória efetiva contra fungos de madeiras, como Coriolus versicolor (podridão branca) e Laetiporus sulfphureus (podridão marrom), em doses muito baixas (100 ppm). O cubenol (7,43 a 13,67\%) foi outro constituinte majoritário identificado nos óleos de $P$. neochilous. Este constituinte apresentou atividade acaricida contra ácaro rajado (Tetranychus urtiae Koth) (Pontes et al., 2007).

O germacreno-D $(9,44 \%)$ foi encontrado apenas no tratamento sem adubação e 1-epi-cubenol $(5,74 \%)$ no tratamento com adubação bovina. Estes constituintes têm atividade antimicrobiana, como relataram Vieira et al. (2009).

Tabela 1. Composição química e percentagem relativa dos constituintes do óleo essencial de plantas de Plectranthus neochilus cultivadas sob diferentes fontes de adubos orgânicos e sem adubação

\begin{tabular}{|c|c|c|c|c|c|}
\hline \multirow{2}{*}{ IK } & \multirow{2}{*}{ Compostos } & \multirow[t]{2}{*}{ Classes } & Sem adubação & Esterco bovino & Esterco avícola \\
\hline & & & \multicolumn{3}{|c|}{$(\%)$} \\
\hline 1177 & Mentol & $\mathrm{M}$ & 0,97 & 2,76 & 1,88 \\
\hline 1198 & Metil chavicol & M & 1,02 & - & - \\
\hline 1347 & $\alpha$-Cubebeno & $\mathrm{S}$ & 0,43 & - & - \\
\hline 1375 & $\alpha$-Copaeno & S & 1,01 & - & 0,84 \\
\hline 1383 & $\beta$-Bourboreno & S & 1,06 & - & 0,79 \\
\hline 1387 & $\beta$-Cubebeno & S & 0,70 & - & - \\
\hline 1419 & $\beta$-Cariofileno & S & 15,06 & - & 1,99 \\
\hline 1429 & $\beta$-Gurjuneno & S & 0,23 & - & - \\
\hline 1455 & $\alpha$-Humuleno & S & 0,99 & - & - \\
\hline 1474 & $\gamma$-Muuroleno & S & 0,48 & - & 1,00 \\
\hline 1480 & Germacreno-D & S & 9,44 & - & - \\
\hline 1492 & Trans-muurola-4(14)dieno & S & 0,24 & - & - \\
\hline 1495 & Epi-Cubebol & S & 1,68 & 1,44 & 2,10 \\
\hline 1498 & $\alpha$-Muuroleno & S & 0,44 & - & 0,98 \\
\hline 1504 & $\beta$-Bisaboleno & S & 0,22 & - & - \\
\hline 1512 & $\gamma$-Cadineno & S & 3,81 & 1,36 & 3,15 \\
\hline 1515 & Cubebol & S & 2,66 & 4,03 & 4,75 \\
\hline 1518 & $\delta$-Cadineno & S & 7,38 & - & - \\
\hline 1521 & Z-Calameno & S & 0,75 & - & 0,69 \\
\hline 1561 & E-Nerolidol & S & 5,71 & 2,40 & 1,00 \\
\hline 1577 & Espatulenol & S & 1,12 & 0,93 & 0,83 \\
\hline 1582 & Óxido de Cariofileno & S & 9,83 & 33,53 & 43,70 \\
\hline 1603 & $\beta$-Oplopenona & S & 0,34 & - & 0,48 \\
\hline 1610 & Epóxido de Humuleno II & S & 0,47 & 1,29 & 1,67 \\
\hline 1628 & 1-Epi-Cubenol & S & 2,60 & 5,74 & 3,66 \\
\hline 1637 & 4(14)8(15)dien-cariofila5- $\alpha$-ol & S & 1,73 & 0,15 & - \\
\hline 1643 & Cubenol & S & 7,43 & 13,67 & 8,62 \\
\hline 1647 & $\alpha$-Muurolol & S & 1,66 & 4,73 & 2,58 \\
\hline 1655 & $\alpha$-Cadinol & S & 8,14 & 20,39 & 11,93 \\
\hline 1670 & E-14-hidroxi-9-epi-cariofileno & S & 1,76 & 2,31 & 0,84 \\
\hline 1690 & 4(15)7-dien-Eudesma-1- $\beta$-ol & S & 1,54 & 1,59 & 0,91 \\
\hline \multicolumn{3}{|c|}{ Total Monoterpenos (M) } & 1,99 & 2,76 & 1,88 \\
\hline \multicolumn{3}{|c|}{ Total Sesquiterpenos (S) } & 88,91 & 93,56 & 92,51 \\
\hline \multicolumn{3}{|c|}{ \% Relativa Total dos Constituintes } & 90,90 & 96,32 & 94,39 \\
\hline \multicolumn{3}{|c|}{ Número de Compostos Identificados } & 31 & 15 & 21 \\
\hline
\end{tabular}

(-) ausente

Rev. Ceres, Viçosa, v. 58, n.5, p. 670-678, set/out, 2011 
Quatro componentes voláteis de uma conífera japonesa (Cryptomeria japonica (Thunb. ex L. f.) D. Don) e, dois desses, o nerolidol e $\delta$-cadineno, encontrados em $P$. neochilous, mostraram alta atividade repelente da coleobroca (Semanstus japonica) (Yatagai et al., 2002). O composto E-nerolidol (5,71\%), encontrado no tratamento controle, evidenciou atividade larvicida em Aedes aegypti (Simas et al., 2004).

Os resultados evidenciam que o tipo de fertilização orgânica influencia, de maneira pronunciada, a produção de biomassa e a composição química, qualitativa e quantitativamente, do óleo essencial. E conforme o objetivo do uso da planta, pode-se induzir a maior produção e acúmulo de um determinado constituinte do que de outro. Por outro lado, não se deve excluir o possível efeito sinérgico de outros constituintes presentes no óleo, que, mesmo em pequenas quantidades, podem mascarar a reconhecida atividade biológica do constituinte. Embora não estivesse no escopo do trabalho, pode-se inferir que o óleo encontrado em boldo pequeno, além seu emprego popular, poderá ser testado em várias atividades biológicas.

\section{CONCLUSÕES}

As fontes de adubo orgânico avaliadas promovem maior produção de biomassa e rendimento do óleo essencial de Plectranthus neochilus, em maior magnitude, com a aplicação de esterco avícola.

Porém, a utilização de diferentes fontes de fertilizantes orgânicos, ou a ausência deles em plantas de P. neochilus, não modifica o teor de óleo essencial produzido.

A composição química qualitativa e quantitativa do seu óleo essencial é significativamente alterada conforme o fertilizante orgânico empregado.

\section{AGRADECIMENTOS}

Ao Conselho Nacional de Desenvolvimento Científico e Tecnológico (CNPq); à Coordenação de Aperfeiçoamento de Pessoal de Nível Superior (CAPES) e à Fundação de Amparo à Pesquisa do Estado de Minas Gerais (FAPEMIG), pela bolsa de estudo, de produtividade, de apoio técnico e pelo apoio financeiro.

\section{REFERÊNCIAS}

Adams RP (2007) Identification of essential oil components by gas chromatography/mass spectrometry. $4^{\text {a }}$ ed. Carol Stream IL, Allured. 804p.

Blank AF, Silva PA, Arrigoni-Blank MF, Silva-Mann \& Barreto MCV (2005) Influência da adubação orgânica e mineral no cultivo de manjericão cv. Genovese. Revista Ciência Agronômica, $36: 175-180$.

Chang ST, Wang SY \& Kuo YH (2003) Resources and ioactive substances from Taiwania (Taiwania cryptomerioides). Journal Wood Science, 49:1-4
Carvalho JG (2007) Adubação verde e compostagem. Lavras, UFLA/FAEPE. 26p.

Carvalho MC, Costa COM, Sousa JS, Silva RHD, Oliveira CL \& Paixão FJR (2005) Rendimento da produção de óleo essencial de capim-santo submetido a diferentes tipos de adubação. Revista de Biologia e Ciências da Terra, 5:1-7.

Cho JY, Chang HJ, Lee SK, Kim HJ, Hwang JK \& Chun HS (2007) Amelioration of dextran sulfate sodium-induced colitis in mice by oral administration of â-caryophyllene, a sesquiterpene. Life Sciences, 80:932-939.

Costa LCB, Pinto JEBP, Castro EM, Bertolucci SKV, Corrêa RM, Reis ES, Alves PB \& Niculau ES (2008a) Tipos e doses de adubação orgânica no crescimento, no rendimento e na composição química do óleo essencial de elixir paregórico. Ciência Rural, 38:2173-2180.

Costa LCB, Rosal LF, Pinto JEBP \& Bertolucci SKV (2008b) Efeito da adubação química e orgânica na produção de biomassa e óleo essencial em capim-limão [Cymbopogon citratus (D.C.) Stapf.]. Revista Brasileira de Plantas Medicinais, 10:16-20.

Corrêa RM, Pinto JEBP, Reis ES, Costa LCB, Alves PB, Niculau ES \& Brant RS (2010) Adubação orgânica na produção de biomassa de plantas, teor e qualidade de óleo essencial de orégano (Origanum vulgare L.) em cultivo protegido. Revista Brasileira de Plantas Medicinais, 12:80-89.

Dool H \& Kratz PD (1963) Generalization of the retention index system including linear temperature programmed gas-liquid partition chromatography. Journal of Chromatography, 11:463471 .

Duarte MR \& Lopes JF (2007) Stem and leaf anatomy of Plectranthus neochilus Schltr., Lamiaceae. Revista Brasileira de Farmacognosia, 17:549-556.

EMBRAPA - Empresa Brasileira de Pesquisa Agropecuária (1997) Manual de métodos de análise de solo. $2^{\text {a }}$ ed. rev. atual. Rio de Janeiro, EMBRAPA CNPS. 212p.

EMBRAPA - Empresa Brasileira de Pesquisa Agropecuária (2006) Sistema brasileiro de classificação de solos. 2a ed. Brasília, EMBRAPA CNPS. 306p.

Fageria NF (1998) Otimização da eficiência nutricional na produção das culturas. Revista Brasileira de Engenharia Agrícola e Ambiental, 2:6-16.

FDA. U.S. Food and Drug Administration. Guidance for industry: analytical procedures and methods validation. (1973). Rules and regulation: title 21 . Food and drugs, food additives, synthetic flavoring substances and adjuvants. Fed Regist (17 May) Washington, DC, USA.

Fernandes ES, Passos GF, Medeiros R, Cunha FM, Ferreira J, Campos MM, Pianowski LF \& Calixto JB (2007) Antiinflammatory effects of compounds alpha-humulene and ()- trans-caryophyllene isolated from the essential oil of Cordia verbenacea. European Journal of Pharmacology, 569:228-236.

Habibi Z, Yousefi M \& Aghaie HR (2008) Chemical composition of essential oil of Salvia persepolitana Boiss. and Salvia rhytidea Benth. from Iran. Journal of Essential Oil Research, 20:1-3.

Javidnia H, Miri R \& Khosravi AR (2007) Composition of the essential oil of Teucrium persicum Boiss. from Iran. Journal of Essential Oil Research, 19:430-432.

Lameira OA \& Pinto JEBP (2008) Plantas medicinais: do cultivo, manipulação e uso à recomendação popular. Belém, Embrapa. $264 \mathrm{p}$.

Lorenzi H \& Matos FJA (2002) Plantas medicinais do Brasil: nativas e exóticas. Nova Odessa, Plantarum. 544p. 
Maia SSS, Pinto JEBP, Silva FN \& Oliveira C (2008) Influência da adubação orgânica e mineral no cultivo do bamburral (Hyptis suaveolens (L.) Poit.) (Lamiaceae). Agrária, 3:327-331.

Mapell NC, Vieira, MC, Heredia NA \& Siqueira JM (2005) Produção de biomassa e de óleo essencial dos capítulos florais da camomila em função de nitrogênio e fósforo. Horticultura Brasileira, 23:32-37.

Palácio CPAM, Biasi LA, Nakashima T \& Serrat BM (2007) Biomassa e óleo essencial de carqueja (Baccharis trimera (Less) DC.) sob influência de fontes e doses de nitrogênio. Revista Brasileira de Plantas Medicinais, 9:58-63.

Pontes WJT, Oliveira JCS \& Câmara CAG (2007) Atividade acaricida dos óleos essenciais de folhas e frutos de Xylopia sericea sobre o ácaro rajado (Tetranychus urticae Koch). Química Nova, 30:838-841.

Rosal LF, Pinto JEBP \& Brant RS (2009) Produção de biomassa e óleo essencial de Plectranthus neochilus Schlechter cultivado no campo sob níveis crescentes de adubo orgânico. Pesquisa Aplicada \& Agrotecnologia, 2:39-44.

Sales JF, Pinto JEBP, Botrel PP, Silva FG, Corrêa RM \& Carvalho JG (2009) Acúmulo de massa, teor foliar de nutrientes e rendimento de óleo essencial de hortelã-do-campo (Hyptis marrubioides) cultivado sob adubação orgânica. Bioscience Journal, 25:60-68.

Silva FC (1999) Manual de análises químicas de solos, plantas e fertilizantes. Brasília, Empresa Brasileira de Agropecuária. 370p.

Silva FG, Pinto JEBP, Cardoso MG, Sales JF, Mol DJS \& Divino SP (2007) Influence of manure and fertilizer on Baccharis trimera (Less.) D. C. growth and essential oil yield. Journal of Herbs, Spices \& Medicinal Plants, 13:83-92.
Simas NK, Lima EC, Conceição SR, Kuster RM \& Filho AMO (2004) Produtos naturais para o controle da transmissão da dengue - atividade larvicida de Myroxylon balsamum (óleo vermelho) e de fenilpropanóides. Química Nova, 27:46-49.

Simões CMO \& Spitzer V (2007) Óleos voláteis. In: Simões CMO, Schenkel EP, Gosman G, Mello JCP, Mentz LA \& Petrovick PR (Eds.) Farmacognosia: da planta ao medicamento. $6^{\mathrm{a}}$ ed. Porto Alegre, UFRGS; Florianópolis, UFSC. p.467-496.

Souza JL \& Rezende P (2006) Manual de horticultura orgânica. $2^{\text {a }}$ ed. Viçosa, Aprenda Fácil. 842p.

Tajbakhsh M, Rineh A \& Khalilzadeh MA (2007) Chemical composition of the essential oils from leaves, flowers, stem and root of Phlomis ofivieri Benth. Journal of Essential Oil Research, 19:501-503.

Vieira DVG, Sousa OV, Yamamoto CH \& Kaplan MAC (2009) Chemical composition and antimicrobial activity of the essential oils of Ageratum fastigiatum (Asteraceae). Records of Natural Product, 3:1 52-57.

Yang D, Michel L, Chaumont JP \& Clerc JM (1999) Use of caryophyllene oxide as an antifungal agent in an in vitro experimental model of onychomycosis. Mycopathologia, 148:7982 .

Yatagai M, Makihara H \& Obra K (2002) Volatile components of japanese cedar cultivars as repellents related to resistance to Cryptomeria bark borer. Journal Wood Science, 48:51-53. 